Check for updates

Cite this: Chem. Commun., 2018, 54, 10268

Received 25th May 2018,

Accepted 8th August 2018

DOI: $10.1039 / \mathrm{c} 8 \mathrm{cc} 04169 \mathrm{e}$

rsc.li/chemcomm

\section{A tetranuclear samarium(II) inverse sandwich from direct reduction of toluene by a samarium(II) siloxide $\dagger$}

\author{
Rory P. Kelly, $\ddagger^{a}$ Davide Toniolo, $\ddagger^{a}$ Farzaneh Fadaei Tirani, ${ }^{a}$ Laurent Maron ${ }^{b}$ and \\ Marinella Mazzanti (D)*a
}

The dinuclear Sm" complex, $\left[\mathrm{Sm}_{2} \mathrm{~L}_{4}(\mathrm{dme})\right]\left(\mathrm{L}=\mathrm{OSi}(\mathrm{OtBu})_{3}\right)$, is easily obtained from the protonolysis reaction of $\left[\mathrm{Sm}\left\{\mathrm{N}\left(\mathrm{SiMe}_{3}\right)_{2}\right\}(\text { thf })_{2}\right]$ with $\mathrm{HOSi}(\mathrm{OtBu})_{3}$. This complex reacts slowly with toluene, resulting in the isolation of the triple-decker arene-bridged $\mathrm{Sm}^{\text {" complex, }}$ $\left[\left\{\mathrm{Sm}_{2} \mathrm{~L}_{3}\right\}_{2}\left(\mu-\eta^{6}: \eta^{6}-\mathrm{C}_{7} \mathrm{H}_{8}\right)\right]$, in $44 \%$ yield. This reactivity provides the first example of unambiguous arene reduction by an isolated $\mathrm{Sm}^{\prime \prime}$ species. In contrast, reduction of $\left[\mathrm{SmL}_{3}\right]_{2}$ afforded the inverse sandwich complex, $\left[\left\{K S m L_{3}\right\}_{2}\left(\mu-\eta^{6}: \eta^{6}-\mathrm{C}_{7} \mathrm{H}_{8}\right)\right]$.

Multi-decker sandwich complexes of the f-elements are of great interest because of their anticipated unique electrical and magnetic properties. Bridging organic spacers may facilitate intermetallic electronic communication, leading to potential application in molecular electronics and molecular magnetism. ${ }^{1-4}$ However, the development of this area is hampered by the limited number of multi-metallic sandwich complexes reported in the literature. $^{4,5}$ Multi-decker complexes based on bridging COT ligands (COT $=\eta^{8}$-cyclooctatetraenyl) are the most developed family of multi-decker f-element sandwich complexes. ${ }^{1,4,6-9}$ Arenes are attractive alternative ligands for the synthesis of multi-decker complexes with potentially interesting magnetic and electronic properties ${ }^{2,10}$ but arene-bridged polynuclear complexes of lanthanides are rare. ${ }^{4,5}$ Only very recently, we reported a unique example of an arene-bridged $\mathrm{Ce}^{\mathrm{II}}$ tetradecker complex supported by siloxide ligands. ${ }^{11}$ The pentanuclear $[\mathrm{K}(2.2 .2 \text {-crypt })]_{2}\left[\left\{\left(\mathrm{KL}_{3} \mathrm{Ce}\right)\left(\mu-\eta^{6}: \eta^{6}-\mathrm{C}_{7} \mathrm{H}_{8}\right)\right\}_{2} \mathrm{Ce}\right]$ complex was obtained by reduction of the $\mathrm{Ce}^{\mathrm{III}}$ complex, $\left[\mathrm{KCeL}_{4}\right]\left(\mathrm{L}=\mathrm{OSi}(\mathrm{O} t \mathrm{Bu})_{3}\right)$, with

\footnotetext{
${ }^{a}$ Institut des Sciences et Ingénierie Chimiques Ecole Polytechnique Fédérale de Lausanne (EPFL), 1015 Lausanne, Switzerland. E-mail: marinella.mazzanti@epfl.ch

${ }^{b}$ Université de Toulouse et CNRS INSA, UPS, CNRS, UMR 5215, LPCNO, 135 avenue de Rangueil, 31077 Toulouse, France

$\dagger$ Electronic supplementary information (ESI) available: Full computational and experimental details, NMR spectra, and detailed X-ray. CCDC 1843438-1843441. For ESI and crystallographic data in CIF or other electronic format see DOI: $10.1039 / \mathrm{c} 8 \mathrm{cc} 04169 \mathrm{e}$

\# These authors contributed equally to the work.
}

10 equiv. of $\mathrm{K}$ in toluene, affording the first example of a multidecker complex obtained from the reduction of a trivalent lanthanide complex in a carbocyclic solvent. Reports of the formation of dinuclear arene-bridged $\mathrm{Ln}^{\mathrm{II} / \mathrm{III}}$ complexes from the reduction of trivalent lanthanides complexes are more numerous. ${ }^{5,12-17}$ Although $\mathrm{Ln}^{\mathrm{II}}$ intermediates are likely to be involved in these reactions, the reduction of toluene or benzene by authenticated $\mathrm{Ln}^{\mathrm{II}}$ complexes has not been confirmed. Here, we report a unique example of an arene-bridged triple-decker $\mathrm{Sm}^{\mathrm{II}}$ complex that formed upon dissolution of the dinuclear $\mathrm{Sm}^{\mathrm{II}}$ siloxide complex, $\left[\mathrm{Sm}_{2} \mathrm{~L}_{4}(\mathrm{dme})\right]\left(\mathrm{L}=\mathrm{OSi}(\mathrm{O} t \mathrm{Bu})_{3}\right)$, in toluene. In contrast, the reduction of the $\mathrm{Sm}^{\mathrm{III}}$ siloxide complex, $\left[\mathrm{SmL}_{3}\right]_{2},{ }^{18}$ with $\mathrm{KC}_{8}$ afforded the unusual arene-bridged $\mathrm{Sm}^{\mathrm{II}}$ dimer, $\left[\left\{\mathrm{KSmL}_{3}\right\}_{2}\left(\mu-\eta^{6}: \eta^{6}-\mathrm{C}_{7} \mathrm{H}_{8}\right)\right]$, among other products.

The reduction of the previously reported $\left[\mathrm{SmL}_{3}\right]_{2}{ }^{18}$ complex with 1 equiv. of $\mathrm{KC}_{8}$ per $\mathrm{Sm}$ atom in toluene at $-40{ }^{\circ} \mathrm{C}$ afforded a mixture of several compounds that crystallized rapidly during reduction. Single crystals of the $\mathrm{Sm}^{\mathrm{II}}$ complex, $\left[\mathrm{KSm}_{2} \mathrm{~L}_{5}\right]$ (1) (see ESI $\dagger)$, and of the arene-bridged complex, $\left[\left\{\operatorname{KSmL}_{3}\right\}_{2}\left(\mu-\eta^{6}\right.\right.$ : $\left.\left.\eta^{6}-\mathrm{C}_{7} \mathrm{H}_{8}\right)\right]$ (2), were isolated from the reaction mixture. The ${ }^{1} \mathrm{H}$ NMR spectrum of the crude reaction mixture after removal of graphite (and crystallized reduction products) shows the presence of a major set of signals assigned to the previously reported $\mathrm{Sm}^{\mathrm{III}}$ complex, $\left[\mathrm{KSmL}_{4}\right],{ }^{19}$ and minor signals assigned to complex 2. Quantitative integration of the signals assigned to $\left[\mathrm{KSmL}_{4}\right]$ indicates that $\left[\mathrm{KSmL}_{4}\right]$ formed in $30 \%$ yield. ${ }^{1} \mathrm{H} \mathrm{NMR}$ studies showed that, once isolated, complex 2 decomposes quickly in toluene solution at room temperature and (more slowly) at $-40{ }^{\circ} \mathrm{C}$, yielding $\left[\mathrm{KSmL}_{4}\right]$ and unidentified products. The presence of multiple reduction products, the low stability of 1 and 2, and their low solubility, prevented their isolation in reasonable amounts. Performing the reaction in the presence of cryptand also led to a mixture of compounds, with [K(2.2.2cryptand)][ $\left.\mathrm{SmL}_{4}\right]$ being the major species. These results differ significantly from what is observed in the reduction of $\left[\mathrm{Ln}\left(\mathrm{Cp}^{\mathrm{R}}\right)_{3}\right]$ complexes $\left(\mathrm{Cp}^{\mathrm{R}}=\mathrm{Cp}^{\prime}=\mathrm{C}_{5} \mathrm{H}_{4}\left(\mathrm{SiMe}_{3}\right)\right.$; or $\mathrm{Cp}^{\prime \prime}=\mathrm{C}_{5} \mathrm{H}_{3}\left(\mathrm{SiMe}_{3}\right)_{2}-1,3$; or $\mathrm{Cp}^{\mathrm{tt}}=\mathrm{C}_{5} \mathrm{H}_{3}-(t \mathrm{Bu})_{2}-1,3$; and $\mathrm{Ln}=\mathrm{Ce}$ or $\left.\mathrm{La}\right)$ with $3-4$ equivalents 


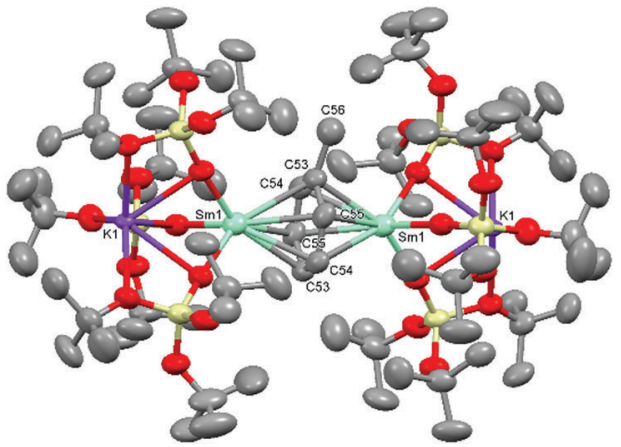

Fig. 1 Molecular structure of complex 2 shown with 50\% probability thermal ellipsoids. Hydrogen atoms have been omitted for clarity. Selected bond lengths $(\AA \AA)$ : $\mathrm{Sm}-\mathrm{O}=2.219(5)-2.241(5), \mathrm{Sm}-\mathrm{C}=2.686(9)-2.752(8)$, mean $\mathrm{C}_{\text {aromatic }}-\mathrm{C}_{\text {aromatic }}=1.416(8)$.

of $\mathrm{K} / \mathrm{KC}_{8}$, which is usually accompanied by loss of an anionic ligand $\left(\mathrm{Cp}^{\prime}=\mathrm{C}_{5} \mathrm{H}_{4}\left(\mathrm{SiMe}_{3}\right)\right)$ and formation of stable arene-bridged $\mathrm{Ln}^{\mathrm{II}}$ complexes of the general formula $\left[\left\{\operatorname{Ln}\left(\mathrm{Cp}^{\mathrm{R}}\right)_{2}\right\}_{2}\left(\mu-\eta^{6}: \eta^{6}\right.\right.$ arene)] (arene $\left.=\left(\mathrm{C}_{6} \mathrm{H}_{6} \text { or } \mathrm{C}_{7} \mathrm{H}_{8}\right)^{1-/ 2-}\right) .^{12,13,20}$

The solid-state structure of 2 (Fig. 1) shows a central toluene bridging two identical $\left\{\mathrm{KSmL}_{3}\right\}$ units. The two potassium ions are both six-coordinate, while the two samarium ions are also both six-coordinate and feature a three-legged piano stool coordination geometry. The Sm-O bond lengths range from 2.219(5)-2.241(5) $\AA$, and they are shorter than the Sm- $\mathrm{O}_{\text {terminal }}$ bond length in the $\mathrm{Sm}^{\mathrm{II}}$ complex, $\left[\mathrm{K}_{2} \mathrm{SmL}_{4}\right]$ (2.381(2) $\left.\AA\right) .{ }^{15}$ The average toluene $\mathrm{C}-\mathrm{C}$ bond length of 1.416(8) $\AA$ is not significantly different from that of free toluene, and so its charge could not be assigned from these distances alone. The $\mathrm{Sm}-\mathrm{C}$ bond lengths (2.686(9)-2.752(8) $⿱$ A) are much longer than those found in 4 (vide infra). The latter values are consistent with the presence of a $\mathrm{Sm}^{\mathrm{II}}$-toluene ${ }^{0}-\mathrm{Sm}^{\mathrm{II}}$ species. Several examples of $\mathrm{Ln}^{\mathrm{II}}{ }^{-}$-neutral arene complexes have been reported where the arene is unsupported, ${ }^{21,22}$ or more often, it is a substituent in $\mathrm{N}$ - or S-donor ligands. ${ }^{23-29}$ Lanthanide complexes of neutral arene ligands ${ }^{5}$ have also been reported that contain $\mathrm{Ln}^{\mathrm{III} 30}$ and $\mathrm{Ln}^{031-33}$ ions. Some degree of reduction of the arene may exist in some of the reported Ln complexes of neutral arenes. In view of these results, we decided to investigate the direct reaction of isolated $\mathrm{Ln}^{\mathrm{II}}$ complexes with toluene.

The dissolution of the previously reported ${ }^{5} \mathrm{Sm}^{\mathrm{II}}$ complex, $\left[\mathrm{K}_{2} \mathrm{SmL}_{4}\right]$, in toluene at room temperature or at $-40{ }^{\circ} \mathrm{C}$ led to the decomposition of the $\mathrm{Sm}^{\mathrm{II}}$ species, affording $\left[\mathrm{KSmL}_{4}\right]$ in quantitative yield. While reduced toluene species are probably formed in this reaction, no arene-bridged intermediate was isolated from this reaction.

In order to identify an alternative route to more stable arene bridged complexes, we decided to explore the possibility of preparing an alkali-metal-free, low-coordinate $\mathrm{Sm}^{\mathrm{II}}$ complex that could stabilize arene-bridged species.

The dinuclear $\mathrm{Sm}^{\mathrm{II}}$ siloxide complex, $\left[\mathrm{Sm}_{2} \mathrm{~L}_{4}(\mathrm{dme})\right](3, \mathrm{~L}=$ $\left.\operatorname{OSi}(\mathrm{O} t \mathrm{Bu})_{3}\right)$, was prepared in $77 \%$ yield by treating $[\mathrm{Sm}\{\mathrm{N}(\mathrm{Si}-$ $\left.\left.\mathrm{Me}_{3}\right)_{2}\right\}_{2}(\text { thf })_{2}$ ] with two equivalents of $\mathrm{HOSi}(\mathrm{O} t \mathrm{Bu})_{3}$ in dme at $-40{ }^{\circ} \mathrm{C}$ (Scheme 1). Complex 3 represents a rare $\mathrm{Ln}^{\mathrm{II}}$ siloxide complex, with only a handful of others known. ${ }^{11,18,19,34}$

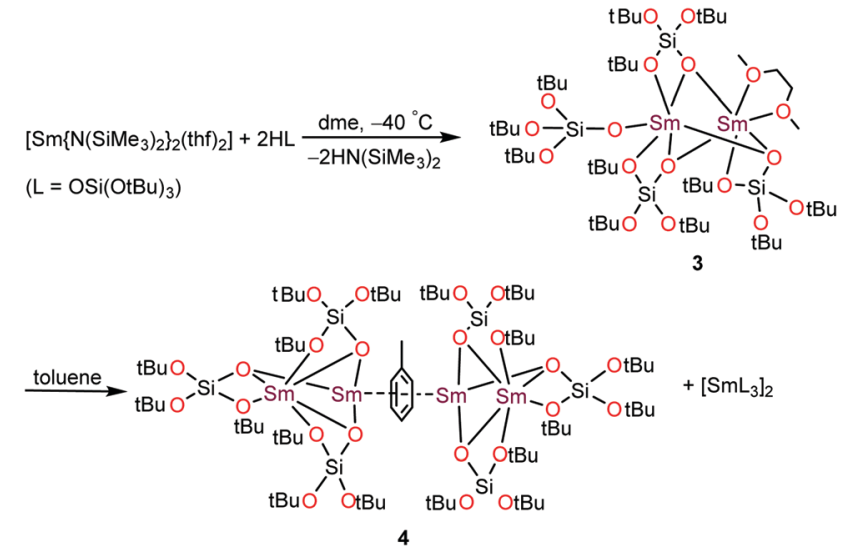

Scheme 1 Synthesis of $\mathbf{3}$ followed by its reaction with toluene to make $\mathbf{4}$.

Storage of a concentrated solution of 3 in dme at $-40{ }^{\circ} \mathrm{C}$ afforded dark brown single crystals of 3 that were suitable for $\mathrm{X}$-ray diffraction studies. The molecular structure of $\mathbf{3}$ features two six-coordinate $\mathrm{Sm}$ ions unsymmetrically coordinated by four siloxide ligands and one dme molecule (Fig. 2). Sm1 is coordinated by one terminal $\kappa^{1}$-siloxide ligand, two bridging $\kappa^{2}$-siloxide ligands and one bridging $\kappa^{1}$-siloxide ligand. On the other hand, Sm2 is coordinated by two bridging $\kappa^{1}$-siloxide ligands, one bridging $\kappa^{2}$-siloxide ligand and one terminal $\kappa^{2}$-dme molecule. The $\mathrm{Sm}-\mathrm{O}_{\text {siloxide }}$ bond lengths range from 2.383(12)-2.692(13) $\AA$, similar to the range observed in the $\mathrm{Sm}^{\mathrm{II}}$ siloxide complex, $\left[\mathrm{K}_{2} \mathrm{SmL}_{4}\right](2.381(2)-2.6659(18) \AA) .{ }^{15}$

Complex 3 is highly soluble in non-polar and polar solvents, and it shows moderate stability in thf at room temperature, with only some decomposition evident after $36 \mathrm{~h}$ at room temperature. The decomposition reaction proceeds with the formation of $\mathrm{Sm}^{\mathrm{III}}$, as evidenced by the detection of $\left[\mathrm{SmL}_{3}(\mathrm{thf})_{2}\right]$ by ${ }^{1} \mathrm{H}$ NMR spectroscopy. This highlights the marked reactivity of complex 3, although it is much more stable in thf than the previously reported $\mathrm{Sm}^{\mathrm{II}}$ complex, $\left[\mathrm{K}_{2} \mathrm{SmL}_{4}\right] \cdot{ }^{19}$ Complex 3 is also stable for up to a week in toluene at $-40{ }^{\circ} \mathrm{C}$ but reacts slowly with toluene at room temperature. Storage of a concentrated toluene

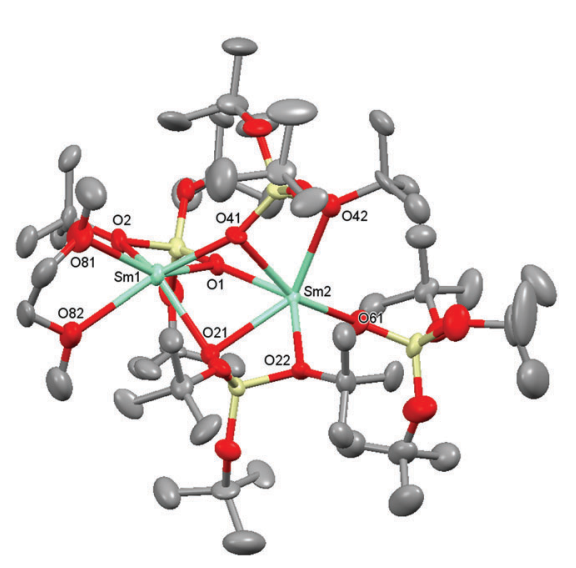

Fig. 2 Molecular structure of complex 3 shown with 50\% probability thermal ellipsoids. Solvent of crystallization and hydrogen atoms have been omitted for clarity. Selected bond lengths $(\AA \AA)$ : $\mathrm{Sm}-\mathrm{O}_{\text {siloxide }}=$ 2.383(12)-2.692(13); $\mathrm{Sm}-\mathrm{O}_{\mathrm{dme}}=2.681(15)-2.710(14)$. 


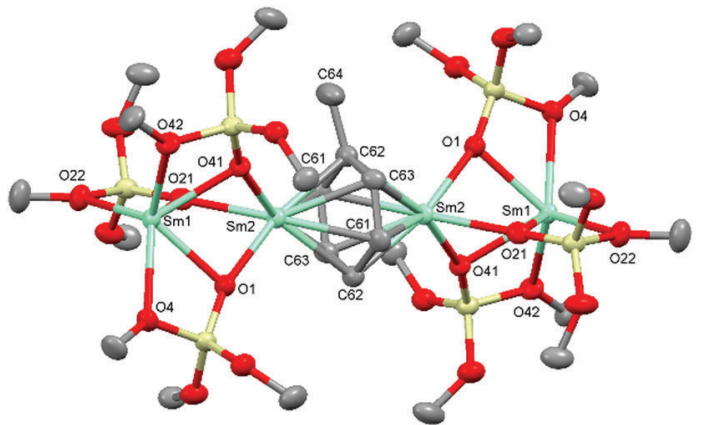

Fig. 3 Molecular structure of complex 4 shown with 50\% probability thermal ellipsoids. Disordered components, the methyl groups of the tBu groups and hydrogen atoms have been omitted for clarity. Selected bond lengths $(\AA \AA): S m-O=2.395(4)-2.620(4), S m 2-C_{\text {aromatic }}=2.523(5)-$ 2.607(5), mean $C_{\text {aromatic }}-C_{\text {aromatic }}=(1.462(7) \AA)$.

solution $(\sim 70 \mathrm{mM})$ of 3 for three days at room temperature and one night at $-40{ }^{\circ} \mathrm{C}$ afforded dark brown crystals of the tetranuclear Sm inverse sandwich complex, $\left[\left\{\mathrm{Sm}_{2} \mathrm{~L}_{3}\right\}_{2}\left(\mu-\eta^{6}: \eta^{6}-\mathrm{C}_{7} \mathrm{H}_{8}\right)\right]$ (4), in 44\% yield (Scheme 1).

${ }^{1} \mathrm{H}$ NMR studies showed that the amount of complex 4 continued to increase after dissolution of $\mathbf{3}$ in toluene until saturation of the solution occurs after three days. The stoichiometry of the reaction leading to $\mathbf{4}$ requires the formation of a second species, and the ${ }^{1} \mathrm{H}$ NMR spectrum of the evaporated reaction mixture in $\mathrm{d}_{8}$-thf indicated it to be the $\mathrm{Sm}^{\mathrm{III}}$ complex, $\left[\mathrm{SmL}_{3}(\mathrm{thf})_{2}\right],{ }^{18}$ also obtained in $44 \%$ yield (as confirmed by quantitative ${ }^{1} \mathrm{H}$ NMR spectroscopy).

Complex 4 is poorly soluble in toluene and only moderately soluble in thf, where decomposition begins rapidly.

The molecular structure of 4 (Fig. 3) features four Sm ions, six siloxide ligands and one central bridging toluene ligand. The two terminal six-coordinate Sm1 ions have the same coordination environment and they are each bound by three bridging $\kappa^{2}$-siloxide ligands. The two $\mathrm{Sm} 2$ ions are bound by three bridging $\kappa^{1}$-siloxide ligands and they both sandwich a bridging $\eta^{6}: \eta^{6}-\mathrm{C}_{7} \mathrm{H}_{8}$ molecule ( $\mathrm{Sm} 2$-centroid-Sm $2=180^{\circ}$ ). The Sm-O bond lengths range from 2.395(4)-2.620(4) A, similarly to those found in $\mathbf{1}$ and $\left[\mathrm{SmL}_{4} \mathrm{~K}_{2}\right],{ }^{15}$ thus supporting the presence of $\mathrm{Sm}$ ions in the +2 oxidation state. The $\mathrm{Sm} 2-\mathrm{C}$ bond lengths range from $2.523(5)-2.607(5) \AA$, and the average $\mathrm{C}_{\text {aromatic }}-\mathrm{C}_{\text {aromatic }}$ bond length $(1.462(7) \AA)$ is indicative of a reduced toluene molecule. ${ }^{12-14,35-39}$

The UV-Vis-NIR spectra of $\mathbf{2}$ and $\mathbf{4}$ in in toluene show broad, intense bands in the visible region, consistent with $\mathrm{f}-\mathrm{d}$ and/or charge-transfer transitions typical of samarium(II). ${ }^{40}$

Unrestricted DFT calculations were carried out on the whole molecules of $\mathbf{2}$ and $\mathbf{4}$ to further investigate their electronic structures. Geometry optimization was carried out at the DFT level (B3PW91) with explicit f-electrons, as already done for similar complexes. ${ }^{11,41}$ Using the f-in-core method, it was possible to confirm the oxidation state of all four samarium centres as +2 in complex 4. The obtained geometry is in excellent agreement with the one obtained with explicit f-electrons, confirming the +2 oxidation state of the four samarium centres. The optimized

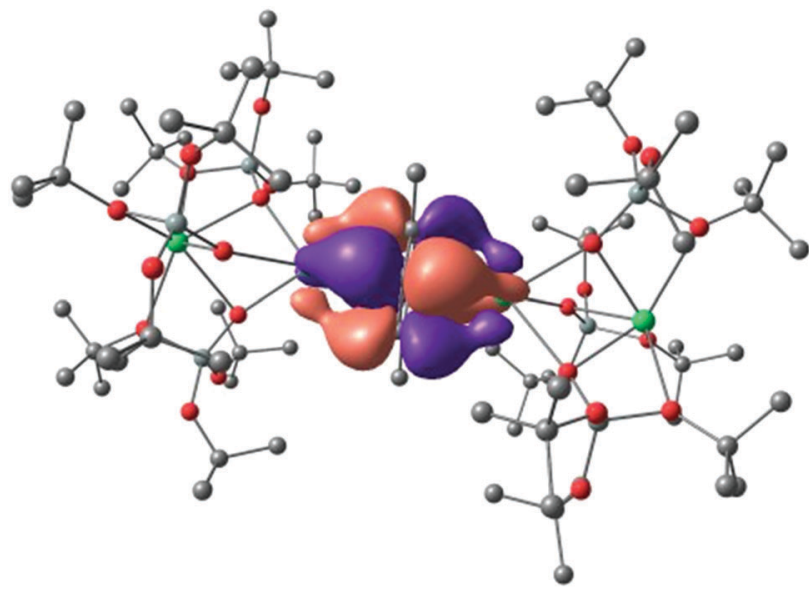

Fig. 4 Highest doubly occupied MO of complex 4.

structure obtained with explicit f-electrons and a spin state of 25 is in good agreement with the experimental one ( $\mathrm{Sm}-\mathrm{O}$ between 2.50 and $2.60 \AA$; and $\mathrm{Sm} 2-\mathrm{C}$ around $2.60 \AA$ ). The average $\mathrm{C}_{\text {aromatic }}-\mathrm{C}_{\text {aromatic }}$ bond length is $1.42 \AA$, in line with a reduced toluene species. This is further highlighted by the nature of the highest doubly occupied molecular orbital of the system (as there are also 24 singly occupied MOs), which is a $\delta$-bond (Fig. 4) involving the toluene $\pi^{*}$ orbital. The occurrence of sequential single-electron transfer of two electrons to the toluene removes the degeneracy of the toluene orbitals due to the first-order Jahn-Teller effect. ${ }^{42}$ Therefore, in the toluene ${ }^{2-}$ here, there is only one doubly occupied former $\mathrm{pi}^{*}$ orbital, and this is consistent with a toluene ${ }^{2-}$. This work provides proof that the first $\mathrm{La}^{\mathrm{II}}$ complex reported by Lappert and coworkers $^{14,41}$ was indeed a genuine $\mathrm{La}^{\mathrm{II}}$ arene anion complex. For the sake of comparison, calculations were also carried out with explicit f-electrons on complex 2. In this complex, the two samarium ions are also in the +2 oxidation state, and the toluene is not reduced; the $\delta$-bond is the LUMO (see ESI $\dagger$ ). A weak bonding interaction between the toluene $\pi$ orbital and the $5 \mathrm{~d} \mathrm{Sm}^{\mathrm{II}}$ orbitals was also found in both complexes.

Thus, computational studies support the formulation of $\left[\left\{\mathrm{KSmL}_{3}\right\}_{2}\left(\mu-\eta^{6}: \eta^{6}-\mathrm{C}_{7} \mathrm{H}_{8}\right)\right]$ as a $\mathrm{Sm}^{\mathrm{II}}$-toluene ${ }^{0}-\mathrm{Sm}^{\mathrm{II}}$ complex, and the formulation of $\left[\left\{\mathrm{Sm}_{2} \mathrm{~L}_{3}\right\}_{2}\left(\mu-\eta^{6}: \eta^{6}-\mathrm{C}_{7} \mathrm{H}_{8}\right)\right]$ as a $\left(\mathrm{Sm}^{\mathrm{II}}\right)_{2}-$ toluene ${ }^{2-}-\left(\mathrm{Sm}^{\mathrm{II}}\right)_{2}$. $\left[\left\{\mathrm{Sm}_{2} \mathrm{~L}_{3}\right\}_{2}\left(\mu-\eta^{6}: \eta^{6}-\mathrm{C}_{7} \mathrm{H}_{8}\right)\right]$ is the second example of an arene-bridged $\mathrm{Ln}^{\mathrm{II}}$ multidecker complex. However, it differs from the recently reported $\mathrm{Ce}^{\mathrm{II}}$ tetra-decker, $\left[\left\{\left(\mathrm{KCeL}_{3}\right)\left(\mu-\eta^{6}: \eta^{6}\right.\right.\right.$ $\left.\left.\mathrm{C}_{7} \mathrm{H}_{8}\right)\right\}_{2} \mathrm{Ce}$, in that it formed without the presence of an alkali metal reductant in the reaction mixture. The reactivity of the dimeric $\left[\mathrm{Sm}_{2} \mathrm{~L}_{4}(\mathrm{dme})\right]$ complex is remarkable, as it is the first case of a clear-cut toluene reduction by a $\mathrm{Sm}^{\mathrm{II}}$ complex, demonstrating its unusual reducing power. These results provide a simple and attractive route to arene-bridged multidecker Ln complexes and future studies will be directed to investigating the possibility of obtaining similar systems with later lanthanide ions.

This work was supported by Ecole Polytechnique Fédérale de Lausanne (EPFL) and by the Swiss National Science Foundation. We thank Dr Rosario Scopelliti for his contribution to the X-ray single crystal structure data collection and analyses, and 
Aurélien R. Willauer for his contribution to synthetic experiments. We thank Dr Euro Solari for elemental analysis. LM is a member of the Institut Universitaire de France. CAlmip is acknowledged for a generous grant of computing time.

\section{Conflicts of interest}

There are no conflicts to declare.

\section{Notes and references}

1 O. T. Summerscales, S. C. Jones, F. G. N. Cloke and P. B. Hitchcock, Organometallics, 2009, 28, 5896-5908.

2 W. L. Huang, J. J. Le Roy, S. I. Khan, L. Ungur, M. Murugesu and P. L. Diaconescu, Inorg. Chem., 2015, 54, 2374-2382.

3 J. J. Le Roy, M. Jeletic, S. I. Gorelsky, I. Korobkov, L. Ungur, L. F. Chibotaru and M. Murugesu, J. Am. Chem. Soc., 2013, 135, 3502-3510.

4 F. T. Edelmann, New J. Chem., 2011, 35, 517-528.

5 M. N. Bochkarev, Chem. Rev., 2002, 102, 2089-2117.

6 W. J. Evans, M. A. Johnston, M. A. Greci and J. W. Ziller, Organometallics, 1999, 18, 1460-1464.

7 W. J. Evans, R. D. Clark, M. A. Ansari and J. W. Ziller, J. Am. Chem. Soc., 1998, 120, 9555-9563.

8 T. Li, J. Wiecko, N. A. Pushkarevsky, M. T. Gamer, R. Koppe, S. N. Konchenko, M. Scheer and P. W. Roesky, Angew. Chem., Int. Ed., 2011, 50, 9491-9495.

9 A. Edelmann, S. Blaurock, V. Lorenz, L. Hilfert and F. T. Edelmann, Angew. Chem., Int. Ed., 2007, 46, 6732-6734.

10 S. S. Liu, J. W. Ziller, Y. Q. Zhang, B. W. Wang, W. J. Evans and S. Gao, Chem. Commun., 2014, 50, 11418-11420.

11 R. P. Kelly, L. Maron, R. Scopelliti and M. Mazzanti, Angew. Chem., Int. Ed., 2017, 56, 15663-15666.

12 C. M. Kotyk, M. E. Fieser, C. T. Palumbo, J. W. Ziller, L. E. Darago, J. R. Long, F. Furche and W. J. Evans, Chem. Sci., 2015, 6, 7267-7273.

13 Y. K. Gun'ko, P. B. Hitchcock and M. F. Lappert, Organometallics, 2000, 19, 2832-2834.

14 M. C. Cassani, D. J. Duncalf and M. F. Lappert, J. Am. Chem. Soc., 1998, 120, 12958-12959.

15 M. D. Fryzuk, L. Jafarpour, F. M. Kerton, J. B. Love, B. O. Patrick and S. J. Rettig, Organometallics, 2001, 20, 1387-1396.

16 M. D. Fryzuk, L. Jafarpour, F. M. Kerton, J. B. Love and S. J. Rettig, Angew. Chem., Int. Ed., 2000, 39, 767-768.

17 M. C. Cassani, Y. K. Gun'ko, P. B. Hitchcock, M. F. Lappert and F. Laschi, Organometallics, 1999, 18, 5539-5547.
18 M. Nishiura, Z. M. Hou and Y. Wakatsuki, Organometallics, 2004, 23, 1359-1368.

19 J. Andrez, J. Pecaut, P.-A. Bayle and M. Mazzanti, Angew. Chem., Int. Ed., 2014, 53, 10448-10452.

20 M. C. Cassani, Y. K. Gunko, P. B. Hitchcock and M. F. Lappert, Chem. Commun., 1996, 1987-1988.

21 S. I. Troyanov, Russ. J. Coord. Chem., 1998, 24, 591-597.

22 A. A. Fagin, M. N. Bochkarev, S. A. Kozimor, J. W. Ziller and W. J. Evans, Z. Anorg. Allg. Chem., 2005, 631, 2848-2853.

23 I. V. Basalov, O. S. Yurova, A. V. Cherkasov, G. K. Fukin and A. A. Trifonov, Inorg. Chem., 2016, 55, 1236-1244.

24 D. Heitmann, C. Jones, D. P. Mills and A. Stasch, Dalton Trans., 2010, 39, 1877-1882.

25 M. G. Gardiner, A. N. James, C. Jones and C. Schulten, Dalton Trans., 2010, 39, 6864-6870.

26 D. Heitmann, C. Jones, P. C. Junk, K. A. Lippert and A. Stasch, Dalton Trans., 2007, 187-189.

27 A. Cofone and M. Niemeyer, Z. Anorg. Allg. Chem., 2006, 632, 1930-1932.

28 M. E. Fieser, C. T. Palumbo, H. S. La Pierre, D. P. Halter, V. K. Voora, J. W. Ziller, F. Furche, K. Meyer and W. J. Evans, Chem. Sci., 2017, 8, 7424-7433.

29 D. P. Halter, C. T. Palumbo, J. W. Ziller, M. Gembicky, A. L. Rheingold, W. J. Evans and K. Meyer, J. Am. Chem. Soc., 2018, 140, 2587-2594.

30 F. A. Cotton and W. Schwotzer, J. Am. Chem. Soc., 1986, 108, 4657-4658.

31 P. L. Arnold, M. A. Petrukhina, V. E. Bochenkov, T. I. Shabatina, V. V. Zagorskii, G. B. Sergeev and F. G. N. Cloke, J. Organomet. Chem., 2003, 688, 49-55.

32 F. G. N. Cloke, Chem. Soc. Rev., 1993, 22, 17-24.

33 D. M. Anderson, F. G. N. Cloke, P. A. Cox, N. Edelstein, J. C. Green, T. Pang, A. A. Sameh and G. Shalimoff, J. Chem. Soc., Chem. Commun., 1989, 53-55.

34 D. J. Duncalf, P. B. Hitchcock and G. A. Lawless, J. Organomet. Chem., 1996, 506, 347-349.

35 P. L. Diaconescu, P. L. Arnold, T. A. Baker, D. J. Mindiola and C. C. Cummins, J. Am. Chem. Soc., 2000, 122, 6108-6109.

36 W. L. Huang, F. Dulong, T. P. Wu, S. I. Khan, J. T. Miller, T. Cantat and P. L. Diaconescu, Nat. Commun., 2013, 4, 1448-1455.

37 B. Vlaisayljevich, P. L. Diaconescu, W. L. Lukens, Jr., L. Gagliardi and C. C. Cummins, Organometallics, 2013, 32, 1341-1352.

38 C. Camp, V. Mougel, J. Pecaut, L. Maron and M. Mazzanti, Chem. Eur. J., 2013, 19, 17528-17540.

39 D. P. Mills, F. Moro, J. McMaster, J. van Slageren, W. Lewis, A. J. Blake and S. T. Liddle, Nat. Chem., 2011, 3, 454-460.

40 M. R. MacDonald, J. E. Bates, J. W. Ziller, F. Furche and W. J. Evans, J. Am. Chem. Soc., 2013, 135, 9857-9868.

41 P. B. Hitchcock, M. F. Lappert, L. Maron and A. V. Protchenko, Angew. Chem., Int. Ed. Engl., 2008, 47, 1488-1491.

42 S. Labouille, F. Nief and L. Maron, J. Phys. Chem. A, 2011, 115, 8295-8301. 